\title{
Lecture
}

\section{Spectral design considerations in artificial lighting}

\section{Luke THORINGTON* and Philip C. HUGHES*}

\section{Introduction}

The spectrum of artificial light for illuminating our interior workplaces has been dictated by the availability of practical light sources and the criteria by which they are evaluated. Thus light is generated practically by hot tungsten wire, by electrical discharges through mercury, sodium and other metal vapors and gases, and by ultraviolet (UV) stimulation of fluorescence; and the criterion by which the light of these sources is evaluated is based on the luminous efficiency of the spectrum, which rates those sources highest which have spectral emission closest to $555 \mathrm{~nm}$, the green-yellow wavelength having peak luminous efficacy of 683 lumens per watt. On this basis the sources of highest color rendering capacity are rated the lowest in luminous efficacy and this accounts for the usage of such poor color rendering sources as cool white fluorescent and high pressure sodium (HPS) in the modern workplace (Fig. 1, Fig. 2).

Given the fact that modern technology can produce almost any light source spectrum desired it
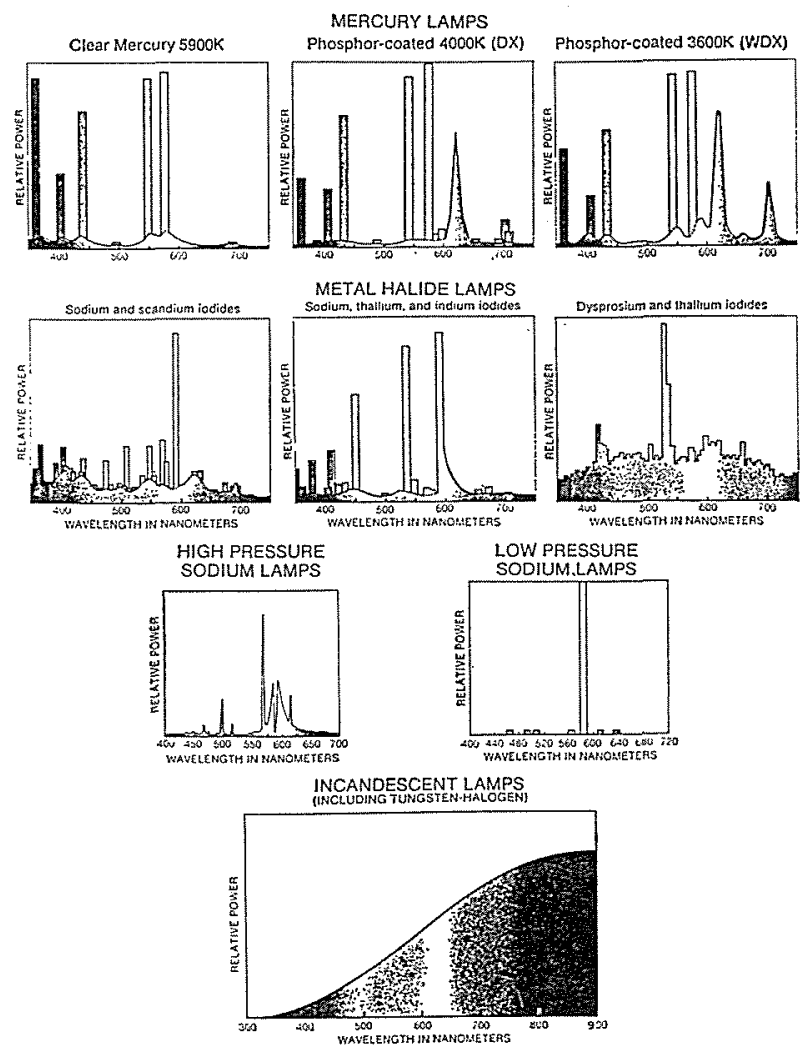

Fig. 1 Relative spectral distribution of discharge lamps and incandescent lamps.

* Duro-Test Corporation, North Bergen, New Jersey 07047, U.S.A.

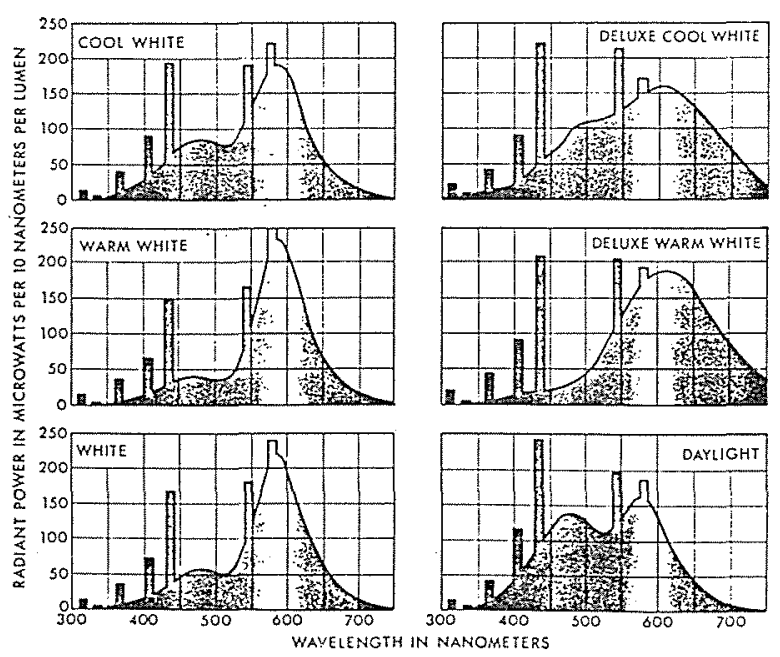

Fig. 2 Spectral distribution of fluorescent lamps.

is realistic and timely to consider whether a meaningful basis exists for using any particular spectrum over another. Heretofore, the purpose of artificially illuminating interior workplaces was primarily to make the task visible. It has now become apparent that light is an important health factor for the workers themselves, and therefore this aspect of light must be given proper attention.

It is the purpose of this paper to examine the spectral criteria for optimizing both the vision and health requirements of people in the artificially lighted workplace and to describe an effective relative spectral power distribution (RSPD) for artificial lighting in the workplace.

\section{Vision}

The spectral range for human vision is from about $360 \mathrm{~nm}$ in the near ultraviolet (UVA) to about $830 \mathrm{~nm}$ in the red. The relative spectral luminous efficiency for photopic vision peaks at about $555 \mathrm{~nm}$ in accordance with the International Commission on Illumination (CIE) $V_{i}$ function. (Fig. 3). However, the $\mathrm{V}_{\lambda}$ function deals only with the luminous aspect of light and tells nothing of the perceptual differences associated with different reflectance spectra. Color and color differences can be crucial to good visual perception in the workplace and, indeed, a matter of safety if the meaning of standard industrial safety colors cannot be correctly perceived. Thus, both luminous and color criteria must be applied for optimizing the spectrum of illuminants for interior workplaces.

In addition to characteristic form and texture, objects have characteristic reflection and transmission spectra which are fundamental to their rec- 


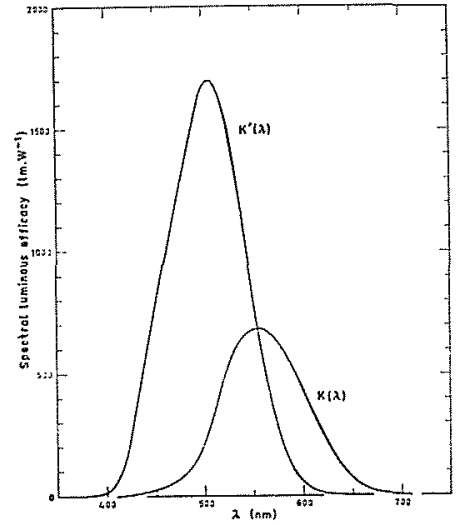

Fig. 3

The spectral luminous efficacies of monochromatic radiation, $K(\lambda)$ for photopic vision and $K(\lambda)$ for scotopic vision, plotted against the wavelength $\lambda$.

ognition and identification. Optimum light should reveal the inherent color characteristics of objects and surfaces, that is, it should have the maximum color rendering capacity. This dictates a uniform (flat) relative spectral power distribution and this results in a nearest correlated color temperature (CCT) of $5464 \mathrm{~K}$. Under a light source with this RSPD and CCT all colors can be seen as maximally characteristic of the environment and not of the illuminant. An example of the latter is the way HPS lighting overpowers the real environment. While this is the worst case example, the industrial designer of artificially illuminated interiors also must contend with spectral distortions induced by most modern light sources. Furthermore, workers have to be content with a much less visually effective environment, which they, unfortunately and unknowingly, tolerate because of chromatic adaptation, but where the end result is reduced visual performance and the associated higher production costs.

Even the performance of tasks in the workplace involving achromatic visual stimuli can be strongly affected by the SPD of the illuminants, as was reported by $\mathrm{H}$. Richard Blackwell at a New York Academy of Sciences (NYAS) conference on medical and biological effects of light in November 1984. He demonstrated that there is a visual performance-related spectral effectiveness factor (SEF) associated with the spectrum of different sources. For example, 7.5 times as much HPS illuminance was found to be required to achieve the same visual performance as metal halide lighting having a 91 CRI and a correlated color temperature of about $5200 \mathrm{~K}$. Underlying this dramatic result is believed to be a related effect between the spectrum of light and focusing.

Another effect of light spectrum on achromatic visual performance results from an artifact of modern office paper production, namely the intro- duction of fluorescent whiteners or brighteners to counteract the normal yellowish color of the paper. Illuminants emitting wavelengths between about 360 and $400 \mathrm{~nm}$ stimulate this fluorescence which increases the brightness of the paper and therefore the contrast between the white paper and black printed matter; human teeth are likewise whitened and brightened noticeably by fluorescence. Chromatic fluorescence is also commonly characteristic of many objects and substances in the natural and interior workplace environments (Fig. 4). There-

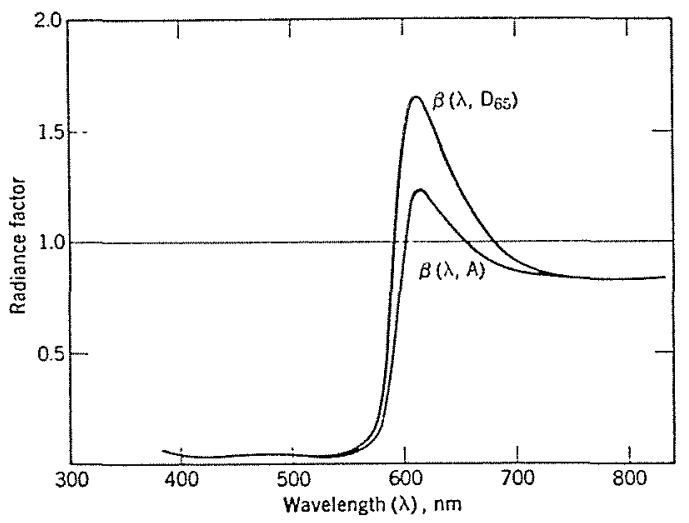

Fig. 4

Spectral radiance factors of a fluorescent object measured under a source with the relative spectral power distribution $S(\lambda)$ of $C I E$ standard illuminant $D_{65}$, and under a source with $S(\lambda)$ of CIE standard illuminant $A$.

fore, their visual appearance is, at least partly, determined by the presence or absence of fluorescence-stimulating wavelengths in the lighting. Colorimetry of colored objects which are fluorescent is complex, and has become a legitimate branch of color science. There are also other important reasons for considering the inclusion of these and still shorter ultraviolet (UV) wavelengths in the optimum spectrum for workplace illuminants.

\section{Health}

The NYAS conference referred to earlier should put an end to doubts about light having meaningful effects on human health. The interest here is to identify those effects which might merit changes in the workplace lighting spectrum in order for people to receive the benefits. There are two which are especially important. One is the photochemical synthesis of vitamin $\mathrm{D}_{3}$ (actually a hormone) in people's skin and the associated sequential improvement in intestinal calcium absorption and bone metabolism (Table 1, Fig. 5). The other involves the eye-mediated indirect suppression of melatonin synthesis in the pineal gland (Fig. 6), the effects of light on a specific state of mental depression known as seasonal affective disorder (SAD), and the effects of light on biological rhythms. 
Table 1 Pre-vitamin $D_{3}$ Action Spectrum and Corresponding Weighted Solar Irradiance.

\begin{tabular}{|c|c|c|c|c|c|}
\hline \multirow[t]{2}{*}{$\lambda(\mathrm{nm})$} & \multicolumn{2}{|c|}{$\begin{array}{l}\text { Solar Irradiance } \\
\mu \mathrm{W} \mathrm{cm}^{-2} \mathrm{~nm}^{-1}\end{array}$} & \multirow{2}{*}{$\begin{array}{l}\text { *2*-Dre-D3 } \\
\text { Action } \\
\text { Spectrum }\end{array}$} & \multicolumn{2}{|c|}{$\begin{array}{l}\text { Weighted Pre-Ds } \\
\text { Irradiance } \\
\mu \mathrm{WD}^{-2} \mathrm{~cm}^{-2} \mathrm{~nm}^{-1}\end{array}$} \\
\hline & I une & Dec. & & June & Dec. \\
\hline 297.6 & 0.4 & 0 & 1.0 & 0.4 & - \\
\hline 300.1 & 1.8 & 0 & .943 & 1.7 & - \\
\hline 302.8 & 4.2 & 0.3 & .675 & 2.84 & .203 \\
\hline 305.5 & 8.2 & 1.4 & .453 & 3.71 & .634 \\
\hline 308.3 & 12.6 & 2.7 & .245 & 3.09 & .662 \\
\hline 311.2 & 18.7 & 4.7 & .150 & 2.8 & .705 \\
\hline 314.2 & 25.6 & 7.5 & .057 & 1.46 & .427 \\
\hline
\end{tabular}

HOLICK: PHOTOBIOLOGY OF VITAMIN D

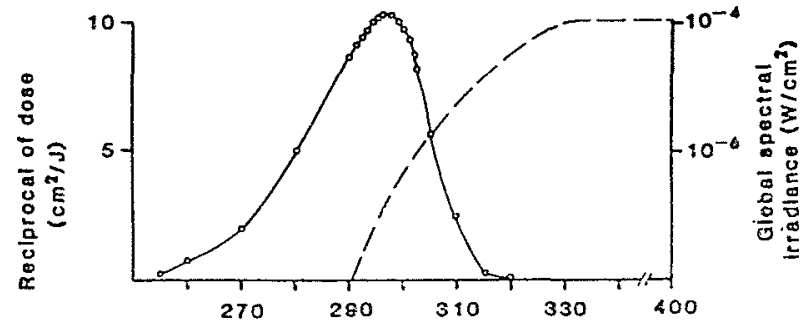

Fig. 5 The action spectrum of preD $D_{3}$ formation from $7-D H C$ in human epidermis (-O-) and the spectral irradiance curve for sunlight (--.). The action spectrum was obtained by plotting the reciprocal of the dose as a function of wavelength. At any wavelength, no more than $5 \%$ of product was nade. The overlay of the curve of the action spectrum with that of the solar spectrum demonstrates the small portion of the solar ultraviolet (UV) spectrum that is involved with the production of pre $_{3}$ from $7-D H C$.

\section{Vitamin D}

Ignorance about sunlight and vitamin $\mathrm{D}$ resulted in many children being deformed by rickets during the industrial revolution of the 18th and 19th centuries. The cause of this was the combination of industrial smog and the congested urban living and working conditions of the times, which all but eliminated people's exposure to the sun's ultraviolet radiation and produce a severe vitamin $D$ deficiency in the population. The subsequent discovery of sunlight's role and the introduction of vitamin D-fortified foods practically eradicated rickets as a major public health concern.

Today a similar scenario is being played out, but this time it is not so much the young as the old who are affected; not the growing skeleton but the aging skeleton; not rickets but osteomalacia and osteoporosis (but see below) ; not UV absorbing smog and urban congestion but UV absorbing diffusers (in workplace lighting) and urban con-

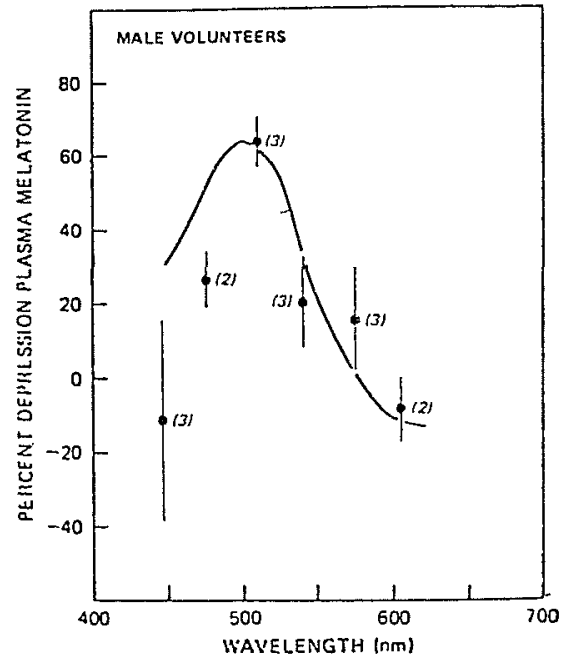

Fig. 6 The above graph demonstrates the mean $\pm S E M$ percent depression of plasma melatonin in male volunteers. The numbers in parenthesis indicate the number of subjects exposed at each wavelength. The curved line is adapted from the work of Wald and Brown (1958) on the spectral sensitivity of human rods.

gestion; not the lack of vitamin D-fortified diets but in spite of vitamin D-fortified diets; not too little vitamin $D$ but both too little (a public health concern in the U.S. and U.K.) and too much (a public health concern in the U.S. but not the U.K. which bans dietary vitamin D); not too little sunshine but both too little (in the workplace) and too much (at the beach), and, finally, not the lack of knowledge but despite our knowledge and because of overconfidence in our vitamin $D$-fortified diet to completely overcome sunlight deficiency, which it has failed to do. All of these comparisons are valid, but while osteomalacia is an adult form of rickets and is clearly vitamin $D$ and sunlight related, osteoporosis is a more complex metabolic bone disease of multiple origins and different treatments. A recent report from the National Institutes of Health in the U.S. revealed that about 20 million people have been diagnosed as having osteoporosis and that another 78 million are at risk. The report recommended, as foremost, increased dietary calcium and, among other things, sunlight exposure as positive steps toward prevention.

To be effective, calcium must be absorbed in the intestine, and it is known that natural sunlight exposure stimulates this. Moreover, it has been shown experimentally that exposure to artificial sunlight, including the UV, does the same thing.

Some compelling reasons for including the solar ultraviolet spectrum in any spectral design consideration of artificial lighting in the workplace are: (1) the existing state of sunlight deprivation 
Table 2 Natural Illuminance Levels vs. Solar Elevation for Clear Sky Conditions.

\begin{tabular}{l|c|c}
\hline \multicolumn{1}{c|}{ Event } & $\begin{array}{l}\text { Elevation of Center of } \\
\text { Sun's Disk Above Horizon (degrees) }\end{array}$ & Approx. Illuminance in Lux \\
\hline Noontime & $70 \sim 90$ & $>100,000$ \\
Twilight starts (Fig. 16) & 8 & $>8,200$ \\
Sun's disk touches horizon & 3 & $>2,800$ \\
Sun's center at horizon & 0 & 730 \\
Sun's upper edge appears to dip below horizon and & -0.6 (Ref. 25) & 512 \\
civil twilight starts & -0.8 (Fig. 15) & 422 \\
Nautical twilight starts & -6.0 & 3.4 \\
Astronomical twilight starts & -62.0 & $9.7 \times 10^{-3}$ \\
Night begins & -18.0 & $6.5 \times 10^{-4}$ \\
\hline
\end{tabular}

of people in the workplace, (2) the established biological necessity of solar UV for human health, (3) the demonstrated danger of vitamin $\mathrm{D}$ intoxication associated with vitamin D-fortified diets, as against the demonstrated safe control inherent in natural vitamin $\mathrm{D}$ photosynthesis in the skin, which is exercised by an exquisite mechanism involving the UVA wavelengths of sunshine and (4) the rising tide of people at risk-especially the elderly-for metabolic bone disease.

Further, there is no basic legal or moral right to deprive people in the workplace of the fundamental, health-related UV component of the natural light environment. "Rights to sunshine" in large cities like Tokyo and New York are already being contested in court but this relates to the placement and height of buildings so as not to rob neighbors of sunshine. Indoor workers are certainly even more deserving of rights to sunshine, including beneficial ultraviolet.

There have been objections, however, about including even very low suberythemal levels of ultraviolet in the workplace on grounds that it may increase the incidence of skin cancer and even malignant melanoma in the workers. This may seem like a reasonable objection but it is not consistent with the fact that (1) interior levels of illuminance in the workplace rarely exceed those of natural global illuminance during sundown on a clear day (about 2800 lux with the center of the sun's disk at the horizon as shown in Table 2), and (2) it has never been demonstrated that any natural or simulated global radiation spectrum, including the UV, has caused any kind of cancer in people at such low levels of illuminance.

Standards for beneficial ultraviolet radiation in the workplace have already been established in Russia by the Ministry of Health, so it may not be too long before the U.S. follows.

\section{Melatonin}

While vitamin $\mathrm{D}$ is photosynthesized directly in the skin (the largest organ of the body), the hormone melatonin is secreted into the bloodstream in the dark by the pineal, a tiny, one-tenth of a gram, organ in the brain. When light enters the eye, signals are generated and sent to the pineal which responds by suppressing melatonin secretion.
The action spectrum for this suppression appears to correspond approximately to the absorption spectrum of rhodopsin, or to the spectral luminous efficiency for scotopic vision, which peaks in the blue-green at $507 \mathrm{~nm}$.

Because of the 24 hour periodicity of the light/ dark cycle, melatonin levels in the blood vary with the same periodicity and can provide the body with a circulating clock mechanism or marker for other endogenous biologic rhythms. Harris R. Lieberman and colleagues at MIT in Cambridge, Mass., U.S.A. reported at the NYAS conference that when the melatonin rhythm itself is disturbed in humans by injecting melatonin into the bloodstream during the daytime, when it is normally at its lowest level, it was found that melatonin had substantial but brief, sedative-like effects on mood and performance. He hypothesized that sufficiently bright light, acting by way of the suppression of melatonin release, can acutely increase alertness or act as a synchronizer of circadian cycles.

Norman E. Rosenthal and his colleagues at the National Institute of Mental Health in the U.S. have demonstrated that certain people who are affected psychopathologically by changes in the circadian cycle of night and day associated with the seasons-specifically the shortening of daylength as winter approaches-are remarkably improved by lengthening their day with about 2500 lux of fluorescent light simulating the natural sun-plussky spectrum. It took up to four days of light treatment for the antidepressant effects to appear, and relapse occurred in the same period if light treatment stopped. He feels that the behavioral, effects of light in this disorder (seasonal affective disorder or $S A D$ ) may be mediated by its suppressive effects on melatonin. A growing number of researchers are finding similar results as Dr. Rosenthal.

Suppression of nighttime melatonin in humans by light was first demonstrated by Alfred J. Lewy, now at the Oregon State Health Center, who has since demonstrated that 2500 lux of simulated sunlight can be scheduled to advance or delay the circadian rhythm of melatonin in people, and that corresponding changes occur in the core body temperature rhythm. Rutger A. Wever of the Max Planck Institute for Psychiatry in Germany considers that the effectiveness of light treatment for 
resetting human circadian rhythms can have practical applications in the treatment of the jet lag syndrome and for synchronizing the rhythms of shiftworkers who are known to incompletely adapt to shifted work schedules.

light is known to have many other effects on health besides vitamin $D$ photosynthesis in skin, suppression of melatonin in the pineal with its (possible) relation to the successful treatment with light of SAD and other circadian rhythm disorders associated with jet lag, shiftwork, and sleep and eating disorders. There are a wide variety of beneficial, therapeutic, and harmful effects of light on people and little question that the unknown far outweigh the known. It is, however, time to consider the necessary changes in indoor workplace lighting to take advantage of those beneficial effects which have already stood the test of time in nature, and these clearly involve changes in the spectrum.

\section{The spectrum of natural light}

Global irradiance is the combination of sunplus-sky radiation at the earth's surface. This constitutes life's natural environmental lighting. Measurement of the spectral distribution of global irradiance for different times of day and year is therefore necessary for the complete description of this lighting. The most exacting and extensive data of this type for both direct solar and global irradiance have been obtained by Mitsuhiro Habu, Mamoru Suzuki and Takehiko Nagasaka of the Electrotechnical Laboratory (ETL) at Tanashi, Tokyo (Fig. 7).

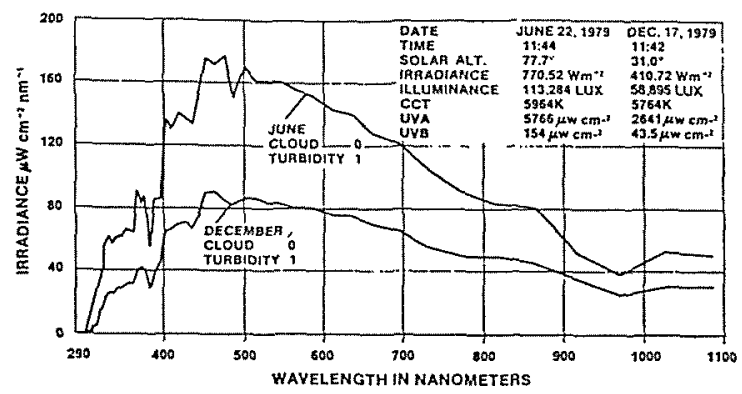

Fig. 7 Global spectral irradiance at Tanashi, Tokyo, Japan during summer and winter solstice periods for clear sky and turbidity corresponding to a visibility between 15 and $80 \mathrm{~km}$.

The data on global irradiance alone, taken between December 1978 and February 1980 consists of 318 sets of 54 data points each for the spectral range $295.1 \mathrm{~nm}$ to $1083.7 \mathrm{~nm}$. The measurements were made for various degrees of cloud cover and atmospheric turbidity, for all seasons of the year, and for various elevations of the sun above the horizon. It is apparent from the spectral data that the relative spectral curves for summer and winter solstices are quite similar and, for the visible, this is further confirmed by the agreement within $200 \mathrm{~K}$ of the computed CCTs.

As an indicator of the spectral consistency of global irradiance, Habu and his colleagues plotted the computed CCT of each spectral run versus the solar angle $\left(>15^{\circ}\right)$ (Fig. 8). These data demonstrate that the relative spectral distribution of visible global irradiance is remarkably independent of sun angle, season, cloud cover and turbidity, the total range of CCT lying between about $5200 \mathrm{~K}$ and $6000 \mathrm{~K}$. Thus on average a remarkably stable spectral mix of sun-plus-sky radiation incident on a horizontal plane is achieved, considering the dynamics and the spectral differences of the sources involved.

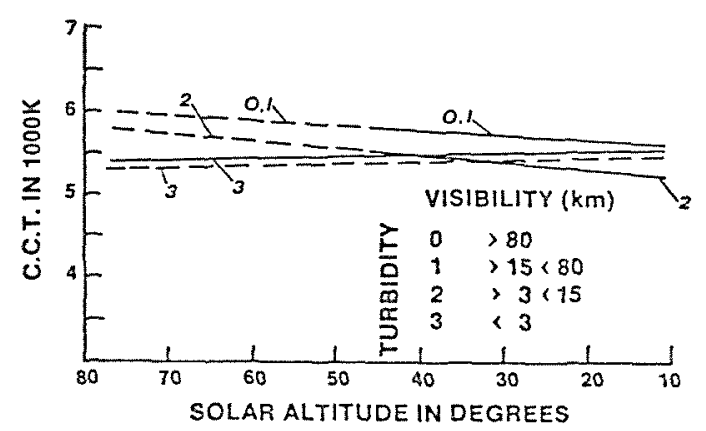

Fig. 8 Regression lines for correlated color temperature of global radiation versus solar altitude for four levels of atmospheric turbidity, all seasons -, and all cloud covers.

While wavelengths shorter than the visible are more strongly scattered and absorbed by the atmosphere, those lying in the near UV (the UVA 315 $400 \mathrm{~nm}$ ) nevertheless maintain a surprisingly uniform relation to the visible, for three wavelengths: $327.5,361.5$ and 395.6 nanometers. The ratio of irradiances at these wavelengths to that of visible irradiance at $565.9 \mathrm{~nm}$ when plotted against CCT for the four seasons shows little effect of season on the UV/visible ratio as a function of CCT and that, as expected, the UV proportion increases with

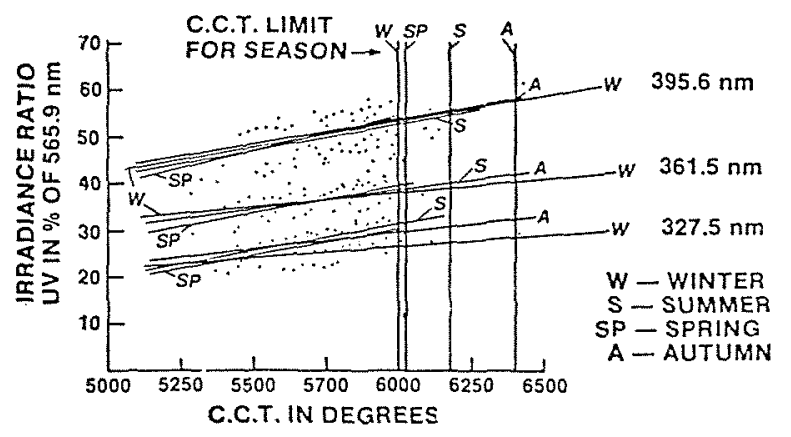

Fig. 9 Regression plots for percent UVA global irradiance of visible global irradiance at $\lambda=$ $565.9 \mathrm{~nm}$ for three UVA wavelengihs and for all seasons as a function of correlated color temperature. 
increasing CCT (Fig. 9). When plotted against solar altitude for four levels of turbidity, there is little dependence of the UV/visible ratio upon degree of turbidity for low sun angles, but at high sun angles and high turbidities, that is, visibility $<3 \mathrm{~km}$, the UV irradiance for each of the three wavelengths, in percent of that at $565.9 \mathrm{~nm}$, is reduced about equally, thus showing little wavelength dependence of the ratio upon turbidity (Fig. 10). Thus the UVA appears to be a fairly stable component of earth's global radiation. It is a different story with the UVB spectrum.

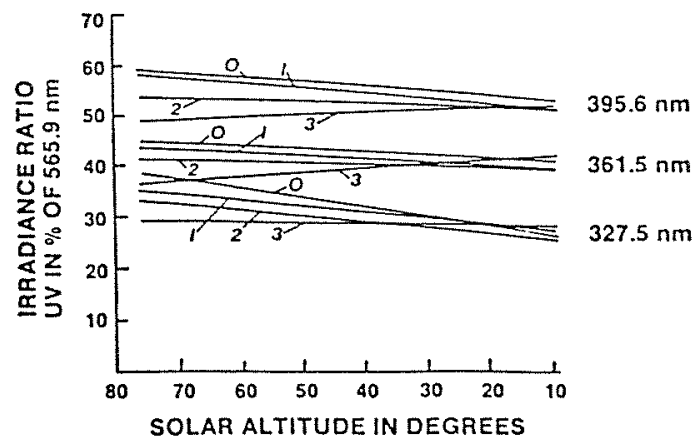

Fig. 10 Regression plots for percent UVA of visible global irradiance for four levels of atmospheric turbidity as a function of solar elevation.

Solar radiation as short as about $286 \mathrm{~nm}$ have been detected, but actual calibrated global spectral irradiance measurements show an effective UVB wavelength cutoff at the earth's surface of about $295 \mathrm{~nm}$ (Fig. 11). UVB radiation is more sensitive to solar angle than longer wavelengths because of the greater path length of the direct beam short-

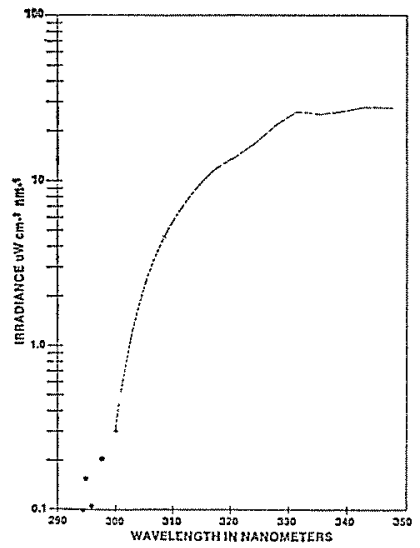

Fig. 11 Spectral irradiance of global $U V$.

wave component associated with lower sun angles. Part of the increased attenuation of the shorter wavelengths at low sun angles is due to selective scattering of the short compared to the longer wavelengths. This scattering has the effect of increasing the diffuse (sky) component of global radiation for the short compared to longer wavelengths. Thus the sky is an important source of natural UVB radiation and is proportionately higher in UVB compared to visible radiation than direct sunlight.

Many factors, including solar angle and change in ozone layer thickness, affect UVB global spectral irradiance. Despite these factors, and even for low sun elevations $\left(31 \sim 32^{\circ}\right)$, the ETL-measured global spectral irradiance at $305.5 \mathrm{~nm}$ (about the most effective natural irradiance for vitamin $D_{3}$ in humans) averages about $95 \mu \mathrm{Wcm}^{-2} \mathrm{~nm}^{-1}$ (SD士.28) for 24 separate days of measurements. Some of the highest readings occurred during heaviest cloud coverage, and even high atmospheric turbidities showed only small, if any, effects.

Long term stability of the integrated global UVB radiation has been demonstrated over a period of four or more years for 14 sites distributed over the United States and foreign countries between $19.5-51.8^{\circ} \mathrm{N}$ latitudes (plus one at $38.0^{\circ} \mathrm{S}$ ) and elevations up to $3.38 \mathrm{~km}$. The conclusion that there is no persistent long-term change in solar UVB radiation reaching the ground appears carefully documented.

The spectroradiometric work at ETL, especially, has helped to define the natural light spectrum and it is worth noting that the spectrum of the sun appears to have been stable, though delicately balanced, at least since humans first appeared.

\section{Spectral design for workplace lighting}

The basis has already been laid for the optimum RSPD for the workplace. It has been shown that it should be flat-an equal RSPD-for vision, because of its maximum color rendering capacity and white color $(5464 \mathrm{~K})$. But it should simulate the natural sun-plus-sky global spectrum for health and well-being since it is the only known light spectrum that has proven safe and effective for this purpose over many generations, skin cancer notwithstanding. It can't be both, and since vision, like vitamin $\mathrm{D}$ synthesis, is a photobiological phenomenon, the spectrum under which it was formed is best. Ary other spectrum is foreign to it and rejectable-just as artificial air or water of different chemical proportions would be rejected by the metabolic system.

The best compromise is the spectrum of natural light closest in CCT to that of the equal RSPD, and that happens to be about the median sun-plussky global radiation spectrum measured at ETL, which has a CCT of about $5500 \mathrm{~K}$ and is also one of the CIE daylight standards.

\section{Practical simulation of natural light}

It is no technical challenge today to produce any spectral power distribution desired in fluorescent lamps, and this is rapidly becoming true of high intensity discharge lamps (HID). The variety of SPDs resulting from this ability demonstrate that 
Table 3 Spectral power distribution for natural environmental light, compared to cool white and artificial sunlight.

\begin{tabular}{|c|c|c|c|c|c|c|c|}
\hline . $\mathrm{um}_{\mathrm{m}}$ & Cool White & CIE D-5500 & $\begin{array}{l}\text { Artificial } \\
\text { Sunlight }\end{array}$ & $2 \mathrm{~nm}$ & Cool White & CIE D-5566 & $\begin{array}{l}\text { Artificial } \\
\text { Sunlight }\end{array}$ \\
\hline 830 & 2.18 & 95.24 & 3.29 & 540 & 134.20 & 141.87 & 177. \\
\hline 820 & 2.21 & 90.64 & 4.60 & 530 & 82.61 & 144.79 & 135. \\
\hline 810 & 3.11 & 81.85 & 5.62 & 520 & 72.2 & 138.95 & 134. \\
\hline \multirow{2}{*}{800} & 2.72 & 93.98 & 5.75 & 510 & 69.6 & 140.06 & 125. \\
\hline & & & & 500 & 72.2 & 139.92 & 118. \\
\hline 790 & 2.74 & 101.65 & 7.34 & 490 & 74.0 & 136.17 & 116. \\
\hline 780 & 3. 32 & 100.12 & 10.2 & 480 & 75.4 & 142.55 & 115. \\
\hline 770 & 3.60 & 105.83 & 12.4 & 470 & 75.0 & 138.80 & 110. \\
\hline 760 & 3.67 & 71.79 & 16.0 & 460 & 67.7 & 139.85 & 104. \\
\hline 756 & 4.63 & 97.76 & 20.2 & 450 & 71.7 & 136.31 & 95.1 \\
\hline 740 & 4.79 & 115.58 & 25.3 & 440 & 149. & 118.90 & 187. \\
\hline 730 & 5.92 & 111.00 & 31.6 & 430 & 115. & 94.30 & 175. \\
\hline 720 & 7.21 & 97.99 & 39.0 & 420 & 40.8 & 99.49 & 57.5 \\
\hline 710 & 8.97 & 117.85 & 48.0 & 410 & 62.2 & 95.55 & 86.1 \\
\hline 700 & 11.0 & 115.13 & 57.4 & 400 & 56.0 & 86.02 & 74.0 \\
\hline 690 & 15.3 & 110.68 & 68.9 & 390 & 20.5 & 51.94 & 28.7 \\
\hline 680 & 18.8 & 125.00 & 78.9 & 380 & 11.5 & 45.46 & 23.4 \\
\hline 670 & 25.0 & 130.61 & 89.6 & 370 & 8.68 & 47.97 & 45.9 \\
\hline 660 & 33.5 & 125.46 & 166. & 360 & 5.57 & 42.81 & 52.5 \\
\hline 650 & 45.9 & 123.52 & 110. & 350 & .98 & 38.90 & 36.1 \\
\hline 640 & 61.6 & 128.25 & 118. & 340 & .16 & 33.47 & 28.4 \\
\hline 630 & 81.5 & 125.61 & 125. & 330 & .32 & 28.86 & 15.4 \\
\hline 620 & 106. & 130.89 & 129. & 320 & 5.24 & 15.62 & 3.6 \\
\hline 610 & $1 \& 4$. & 133.14 & 129. & 310 & 13.8 & 2.93 & 17.5 \\
\hline 600 & 160. & 131.17 & 129. & 300 & 3.44 & .03 & .3 \\
\hline 590 & 183. & 126.99 & 126. & 290 & .66 & 0 & .3 \\
\hline 580 & 226. & 135.75 & 157. & & & & \\
\hline 570 & 192. & 135.20 & 121. & & & & \\
\hline 560 & 163. & 138.95 & 121. & & & & \\
\hline 550 & 180. & 143.12 & 171. & & & & \\
\hline
\end{tabular}

the main design criterion is not that of simulating natural light but maximizing lumens.

It has been over 19 years now that a practical fluorescent lamp simulating the CIE $D_{55}$ spectrum was introduced into the market (Table 3, Table 4). In spite of the fact that the lamp delivered $30 \%$ less lumens than the corresponding cool white lamp-still the workhorse of the commercial world-it proved a marketing success simply because of its high CRI and neutral color. More research (over 200 published articles) on photobiological effects of this practical source on plants, animals and humans has been done than for any other general purpose light source in the world and it is ongoing. It has been demonstrated to stimulate intestinal calcium absorption, suppress melatonin, increase visual acuity, reduce fatigue, and to be effective in treating $S A D$ in adults and children.

It has now been 10 years this November ('85) since a similar article on spectral design of artificial lighting was published in Lighting Design and Application, and it was just brought to my attention. The recommendations made at that time are included for comparison with those proposed in this paper (Table 5).
Table 4 Artificial sunlight lamp and spectrum characteristics (40-watt rapid start)

\begin{tabular}{|c|c|}
\hline Lumens & 2200 \\
\hline Chromaticity & $\begin{array}{l}x=.332 \quad y=.348 \\
\text { (within 3-step MacAdam ellipse) }\end{array}$ \\
\hline $\begin{array}{l}\text { Nearest Correlated Color } \\
\text { Temperature }\end{array}$ & $5500 \mathrm{~K}$ \\
\hline CIE Color Rendering Index & 91 \\
\hline Irradiance per Footcandle & 4.4 microwatts $/ \mathrm{cm}^{2}$ \\
\hline $\begin{array}{l}\text { Photon Density per Foot- } \\
\text { candle }\end{array}$ & $12 \times 10^{12}$ photons $/ \mathrm{sec} . \mathrm{cm}^{2}$ \\
\hline Erythemal Ultraviolet* & $\begin{array}{l}2.2 \text { milliwatts } \\
\text { (equivalent to } 1 \text { MPE at a level } \\
\text { of about } 770 \text { footcandles for } 8 \\
\text { hours exposure) }\end{array}$ \\
\hline Bactericidal Ultraviolet & $\begin{array}{l}900 \text { microwatts } \\
\left(0.5 \text { milliwatts } / \mathrm{ft}^{2} \text { corresponds }\right. \\
\text { to an illumination level of } 1250 \\
\text { footcandles) }\end{array}$ \\
\hline
\end{tabular}

* Weighted according to standard erythemal effectiveness curve.

** Weighted according to standard bactericidal effective. ness curve.

It is a great honor to have been invited by the Illuminating Engineering Institute of Japan to prepare this paper. 
Table 5

The RSPDs for lighting the places where people work routinely should.

\begin{tabular}{|c|c|}
\hline $\begin{array}{l}\text { from the stadpoint of: } \\
\text { Visual perception }\end{array}$ & $\begin{array}{l}\text { provide: } \\
\text { a white light of minimum CRI of } 90 \text { and sufficient uv to excite optical } \\
\text { brighteners and natural luminescent objects such as teeth (which have } \\
\text { an inherent optical brightener!). } \\
\text { stimulation, the potential for pleasantness, the sense of well being and a }\end{array}$ \\
\hline $\begin{array}{l}\text { Energy conservation } \\
\text { Health and safety }\end{array}$ & $\begin{array}{l}\text { a single emission line or narrow-band centered at } 555 \mathrm{~nm} \text {. } \\
\text { radiation, }>290 \mathrm{~nm} \text { and effective at least for vision, vitamin D synthesis } \\
\text { and metabolism, pineal response, all human light-induced or light-synchro- } \\
\text { nized rhythms, intestinal calcium absorption, growing plants, inactivating } \\
\text { pathogenic organisms, and raising domestic animals. }\end{array}$ \\
\hline Human performance & $\begin{array}{l}\text { for the best visual perception, most desirable psychological responses, and } \\
\text { a safe and healthful optical radiation environment. }\end{array}$ \\
\hline Practicality and cost & $\begin{array}{l}\text { (be) achievable from a single light source available in required geometries, } \\
\text { but not requiring auxiliary equipment or protective shielding. }\end{array}$ \\
\hline Teleology & $\begin{array}{l}\text { for a visual and actinic optical radiation environment within the range of } \\
\text { global radiation spectra found in nature. }\end{array}$ \\
\hline Legality & for a radiation environment that fulfills all relevant laws and infringes none. \\
\hline
\end{tabular}

\section{Bibliography}

Baker, K. S., R. C. Smith and A. E. S. Green. 1982. Middle ultraviolet irradiance at the ocean surface: measurements and models. In: The role of solar ultraviolet radiation in marine ecosystems. J. Calkins, Ed. NATO Conference Series IV. Vol. 7: 79 91, Plenum Press. New York.

Bener, P. 1963. Investigation on the influence of clouds on ultraviolet sky radiation. U.S. Dept. of Commerce, National Bureau of Standards, Contract AF61(052)618

Bener, P. 1972. Approximate values of intensity of ultraviolet radiation for different amounts of atmospheric ozone. AD752 115:24. National Technical Information Service. United States Dept. of Commerce, Springfield, Va.

Berger, D., F. Urbach and R. Davies. 1968. The action spectrum of erythema induced by ultraviolet radiation. In: Proceedings of the 13th International Congress of Dermatology, pp. 1112-17. Spring-Verlag, New York. Berger, D. S. and F. Urbach. 1982. A climatology of sunburning ultraviolet radiation. Photochemistry \& Photobiology 35: 187 92.

Biberman, L. M., L. Dunkelman, M. L. Fickett and R. G. Finke. 1966. Levels of nocturnal illumination. U.S. Dept. of Commerce, National Bureau of Standards AD632918.

Bird, R. D., R. L. Hustron, A. W. Kliman and H. G. Eldering. 1982. Solar spectral measurements in the terrestrial environment. Applied Opties 21-8: 1430 36. Blackwell, H. R. 1985. Effects of light source spectral distribution upon visual functions. The medical and biological effects of light, Annals of the New York Academy of Sciences, 453: 340 53.

Buchbinder, L. 1941. Studies on microorganisms in simulated room environments. III. The survival rates of streptococei in the presence of natural, daylight and artificial illumination. Journal of Bacteriology 42: $353 \sim 66$.

Commission Internationale de L'Eclairage. 1974. Method of measuring and specifying colour rendering properties of light sources. No. 13.2 (TC3.2).

Commission Internationale de L'Eclairage. 1983. The basis of physical photometry. No. 18.2 (TC1.2).

Cremer, R.J. 1958. Influence of light on the hyperbilirubinemia of infants. The Lancet 1: 1094.

Dantsig, N. M., D. N. Lazarev and M. V. Sokolov. 1967.
Ultra-violet installations of beneficial action. Commissione Internationale de l'Eclairage Publication No. P67.20 .

Diffey, B. L. 1977. The calculation of the spectral distribution of natural ultraviolet radiation under clear day conditions. Physics in Medicine \& Biology 22-3: $309 \sim 16$.

Fitzpatrick, T. B. 1974. Sunlight and man. Edited by T. B. Fitzpatrick. University of Tokyo Press. Tokyo. Frohlich, C. and C. Wehrli. 1981. Spectral distribution of solar irradiance from 25000 to $250 \mathrm{~nm}$. World Radiation Center. Davos, Switzerland.

Gerstenberger, H. J. and A.J. Horesh. 1931. Journal of the American Medical Assoc. 97: 766.

Giese, A. C. 1976. Living with our Sun's ultraviolet rays. Plenum Press. New York.

Goldberg, B. 1982. Radiometric measurements in the UV-B region of daylight. In: The role of solar ultraviolet radiation in marine ecosystems. J. Calkins, Ed. NATO Conference Series IV. Vol. 7: 121 29, Plenum Press. New York.

Goodman, J. R. 1973. Changes in liver during phototherapy. Clinical Research 21: 319.

Gordon, D. and H. Silverstone. 1976. World-wide epidemiology of pre-malignant and malignant cutaneous lesions. In: Cancer of the skin. pp. 405 34, Saunders, Philadelphia.

Greiter, F., G. Guttman and N. Bachl. 1979. The influence of artificial and natural sunlight upon various psychological and physical parameters of the human organism. 7th Annual Meeting of the American Society for Photobiology. Pacific Grove, California.

Habu, M., M. Suzuki and T. Nagasaka, 1981. 1982, 1983. Measurement of the solar spectral irradiance at Tanashi, Tokyo (I, II, III). Researchers of the Electrotechnical Laboratory Nos. $812,813,830$.

Hasting:s, J.W. 1964. The role of light in persistant daily rhythms. In: Photophysiology, edited by A.C. Giese, Vol. 1, p. 353. Academic Press, New York.

Hatfield, J. L., P. J. Smietana, Jx., J. J. Carroll, R. G. Flocchini and R.H. Hamilton. 1981. Land, air and water resources papers. No. 10005. University of California Davis. Davis, California.

Hausser, K. W. and W. Vahle. 1922. The dependence of light induced erythema and pigment formation upon the frequency (or wavelength) of the inducing radiation. Strahlentherapie 13: $41 \sim 71$.

Himmelfarb, P. A. Scott and P. S. Thayer. 1970. Bac- 
tericidal activity of a broad-spectrum illumination source. Applied Microbiology 19: 1013 14.

Holick, M. F. and J. T. Potts, Jr. 1983. Chapter 340. Vitamin D. In: Harrison's Principles of Internal Medicine, pp. 1944 49, McGraw-Hill Book Co., New York. Hughes, J. E., D. C. Morgan, P. A. Lambton, C. R. Black and H. Smith. 1984. Photoperiodic time signals during twilight. Plant Cell and Environment 7: 269 77.

Hughes, P. C. 1977. The contribution of lighting to productivity and quality of work life. Proceedings of the AIS.

Hughes, P. C. and R. M. Neer. 1981. Lighting for the elderly: A psychobiological approach to lighting. Human Factors 23-1: 65 85.

Hughes, P. C. 1983. An examination of the beneficial action on natural light on the psychobiological system of man. In: Proceedings of the 20th Session, CIE Publication 56: D603 4.

Kaufman, J. E. and H. Haynes, Eds. 1981. IES Lighting Handbook. Reference Volume:- 1-16, Illuminating Engineering Society of North America, New York. Kondratyev, K. Ya. 1969. Radiation in the atmosphere. Academic Press, New York.

Kostkowski, H. J., R. D. Saunders, J. F. Ward, C. H. Popenoe and A. E. S. Green. 1982. Measurement of solar terrestrial spectral irradiance in the ozone cutoff region. In: National Bureau of Standards Technical Note 910-5, Self-study manual on optical radiation measurements, Part III-Applications. Chapter 1. United States Dept. of Commerce. Washington, D.C. Lynch, H.. J., D. C. Jimerson, Y. Ozaki, R. M. Post, W. E. Bunney, Jr. and R. J. Wurtman. 1978. Entrainment of rhythmic melatonin secretion in man to a 12hour phase shift in the light/dark cycle. Life Sciences 23: $1557 \sim 64$

Maas, J. B., J. K. Jayson and D. A. Kleiber. 1974. Effects of spectral differences in illumination on fatigue. Journal of Applied Psychology 59: 524 26.

MacLaughlin, J. A., R. R. Anderson and M. F. Holick. 1982. Spectral character of sunlight modulates photosynthesis of previtamin $\mathrm{D}_{3}$ and its photoisomers in human skin. Science 216 (4549): 1001 03.

Mecherikunnel, A. T., A. G. Gatlin and J. C. Richmond. 1983. Data on total and spectral solar irradiance. Applied Optics 22-9: 1354 59.

Nebolsin, S. I. 1949. Trans. Cent. Inst. Weather Predictions, No. 10-37: U.S.S.R.

Neer, R. M., M. Clark, V. Friedman, R. Belsey, M. Sweeny, Buonchristiani and J. Potts, Jr. 1977. Environmental and nutritional influences on plasma 25hyroxyvitamin $\mathrm{D}$ concentration and calcium metabolism in man. In: Vitamin D: Biochemical, Chemical and Clinical Aspects Related to Calcium Metabolism, edited by A. W. Norman, K. Schaefer J. W. Coburn, H. F. Deluca, D. Fraser, H. G. Grigolet and D.v Herrath, Walter de Gruyter, Berlin.

Neer, R. M., T. Davis, A. Walcott, S. Koshi, P. Shepis, I. Taylor, L. Thorington and R.J. Wurtman. 1971. Stimulation by artificial lighting of calcium absorption in elderly human subjects. Nature 229: 255 57. Nir, I. 1978. Journal of Neural Transmission Suppl 13: $225 \sim 44$.

Parrish, J. A., R. R. Anderson, F. Urbach and D. Pitts. 1978. UV-A: Biological Effects of Ultraviolet Radiation with Emphasis on Human Responses to Long- wave Ultraviolet. Plenum Press, New York.

Rosenthal, N. E., D. A. Sack, G. J. Carpenter, B. L. Barry, W. B. Mendelson and T. A. Wehr. 1985. Antidepressant effects of light in seasonal affective disorder. American Journal of Psychiatry 142-2: 163 70.

Rozenberg, G. V. 1966. Twilight, A study of atmospheric optics. Plenum Press, New York.

Seliger, H.H. 1965. Light: Physical and Biological Action. Academic Press, New York.

Shellow, W. V. R. and A. M. Kligman. 1968. An attempt to produce elastosis in aged human skin by means of ultraviolet irradiation. Journal of Investigatve Dermatology 50 : 225 26.

Smith, H. 1975. Phytochrome and Photomorphogenesis : An Introduction to the Photocontrol of Plant Development. McGaw-Hill, London.

Speck, W. T. 1976. Intracellular dioxyribonucleic acidmodifying activity of phototherapy lights. Pediatric Research 10: 535 55.

Spivack, M. and J. Tamer. 1984. Light and color: A designers' guide. American Institute of Architects Service Corporation, Washington, D.C.

Stair, R. and R. Johnston. 1953. Ultraviolet spectral radiant energy reflected from the moon. Journal of Research of the NBS 51 : $81 \sim 84$.

Tarrant, A. W. S. and J. R. Brock. 1976. Commissione Internationale 1'Eclairage Publication No. 36.

Thorington, L. 1985. Spectral, irradiance, and temporal aspects of natural and artificial light. Annals of the New York Academy of Sciences 453: 28 54:

Thorington, L., L. Parascandola and L. Cunningham. 1971. The illuminant in the prevention and phototherapy of hyperbilirubinemia. Journal of the Illuminating Engineering Society 1-1: 33 41.

United States Naval Observatory. 1962. Tables of sunrise, sunset, and twilight. United States Government Printing Office. Washington, D.C.

Urbach, F., D. B. Rose and M. Bonnem. 1972. In: Environment and Skin Cancer 355 71. Williams and Wilkins, Baltimore.

Volkova, N. V. 1967. Experience in the use of erythemic ultraviolet radiation in the general lighting system of a machine shop. Gigienai Sanitariya 32: 109 11.

Wetterberg, L. 1978. Melatonin in human. Physiological and Clinical studies. In: The Pineal Gland, edited by I. Nir, R. J. Reiter and R. J. Wurtman. SpringerVerlag, New York.

Wilson, R. C. and C. P. Butler. 1978. Total solar irradiance at Table Mtn. California 1926 77. Solar Energy 21: $351 \sim 52$.

Wurtman, R.J. 1975. The effects of light on the human body. Scientific American 233: 68 77 .

$\mathrm{Xu}, \mathrm{H} .1983$. A study of the colour rendering capacity of a light source. Lighting Research and Technology 15-4: $185 \sim 89$.

Wyszecki, G. and W. S. Stiles. 1982. Color science: Concepts and methods, quantitative data and formulae. 2nd edit: 256. J. Wiley \& Sons, Inc., New York.

Zamkova, M. A. and E. I. Krivitskaya. 1966. Effect of irradiation by ultraviolet erythema lamps on the working ability of school children. Gigiena i Sanitariya 31: 41 44.

Zilov, Ju. D. 1971. In: Ultraviolet Radiation, pp. 237 41, Moscow Medicine, Moscow.

Received 6 Feb. 1986. 